\title{
The Use of Business Process Modelling in Software Cost Estimation
}

\author{
1Oga, R.O. \& ${ }^{2}$ Egbokhare, F.A. \\ 1Department of Physical Science, Benson Idahosa University, Benin City, Nigeria \\ 2Department of Computer Science, University of Benin. Benin City, Nigeria \\ E-mail: oga.ruthie@gmail.com
}

\begin{abstract}
Business process modelling aids in an extensive understanding of a process. An organisation process can be adequately analysed, estimated, executed and integrated through its business processes. In this paper we propose the use of business process modelling and analysis in predicting software cost estimates. Using this approach, a minimum set of software requirements were first obtained from the users. These requirements were subsequently decomposed as set of activities and tasks for which cost estimates are drawn. It was observed that using the Business Process Modelling approach will guide a cost estimator to determine the relevant parameters to consider while drawing cost estimates to achieve more realistic outcomes.
\end{abstract}

Keywords: Cost Estimation, Business Process Modelling, Case Study \& Information System Development

CISDI Journal Reference Format

Oga, R.O. \& Egbokhare, F.A. (2019): The Use of Business Process Modelling in Software Cost Estimation. Computing, Information Systems, Development Informatics \& Allied Research Journal. Vol 9 No 1.Pp 7-14. Available online at www.cisdijournal.org DOI Affix - https://doi.org/ 10.22624/AIMS/CISDI/V10N1P2

\section{INTRODUCTION}

Software Cost Estimation (SCE) is the process of predicting the effort, resources and cost for developing a software system (Zaid et al., 2008; Shekhar and Kumar, 2016). A major goal of SCE is to determine the resources required for a project in order to organise and prioritize the development plan to achieve project success. SCE is considered as one of the difficult and complex activities in a software project Lang et al., (2011) and oftentimes, cost estimates are obtained early in the software life cycle after a minimal set of software requirements obtained from the users/stakeholders. An important indicator frequently considered in most estimation models is the project size (Kapoor and Gupta, 2016) which may not always be available at the inception stage of a project. A method that enables an estimator to model the users' problem in terms of the activities and tasks performed will simply the task and help in the identification of the appropriate parameters for which cost estimates should be drawn.

To this end, this paper proposes a Business Process Modelling (BPM) Approach as a first stage in any cost estimation effort. A business process is a set of coherent related tasks performed to achieve a well-defined business outcome (Yan et al., 2007). A business process encompasses a number of events, activities and tasks. A task is a single unit of work that is well defined while an activity may encompass several tasks. In addition to events and activities, a typical process involves decision point stages when a decision is made that affect the way the process is executed. These chain of events, activities and decisions are called Processes (Marlon et al.2013). A process involves a number of actors, human actors, organizations or software systems acting on behalf of human actors or organizations. 


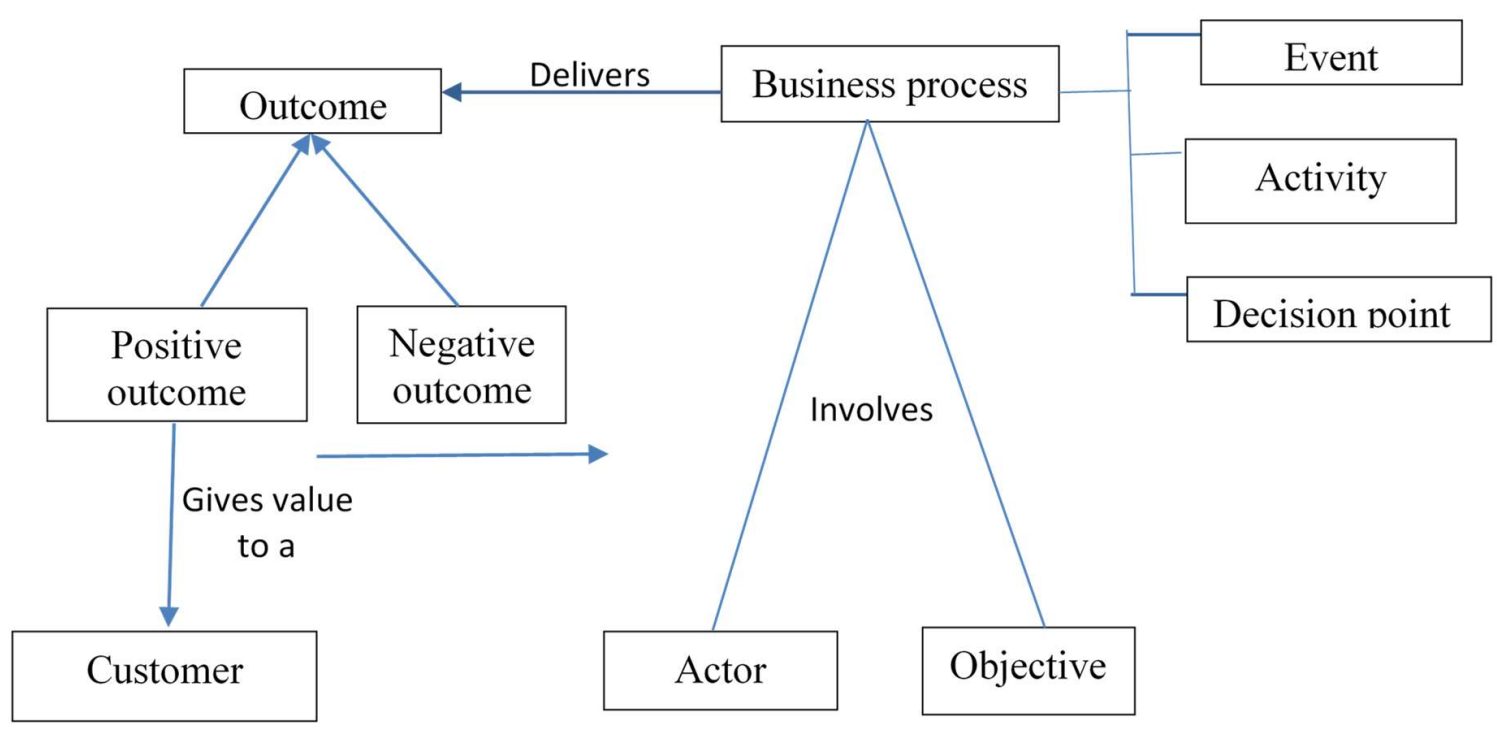

Figure 1: Components of a Business Process (Marlon et al., 2013)

Guided with this description of a business process, we define Business Process Modelling (BPM) as a body of methods, techniques and tools to discover, analyse, redesign, execute and monitor business processes (Yan et al., 2007). A business Process model represents current or future desired organisational behaviour in order to achieve various purposes (Aldin and de Cesare, 2011). A key benefit of modelling the user's problem as a business process is that apart from providing each user function as a distinct entity for refinement during cost estimation, possible requirements changes (requirements volatility) is absorbed within the model as a future behaviour that may manifest based on the current requirements and process flow. In BPM, Processes that add value gradually become the key principles of organising a business rather than focusing only on the functional hierarchy perspective. Understanding the user's problem as a set of business processes helps to facilitate a successful start of the system development project since it gives an ideal view of the activities in the user's domain.

\section{METHODOLOGY}

A Case study method was used in this paper to explore the use of BPM approach software engineering for identifying necessary parameters for cost estimation in a Hospital Information System. Case study research is suitable when the proposed research addresses a contemporary phenomenon, which the researcher has no control over, the research is largely exploratory, and addresses the how and why questions (Yin, 1994). A case study is an empirical enquiry that investigate a contemporary phenomenon within its real-life context, especially when the boundaries between phenomenon and context are not clearly evident (Yin, 1984). It also helps to explore and investigate existing facts through detailed investigation of defined number of events, and their relationships Yin (1984). A typical case study focuses on defining the case; selecting the case(s); collecting and analysing the data; interpreting data; and reporting the findings.

A single case study method using a Hospital as a Business Process was adopted in this project. In this section, application of business process modelling for cost estimation for the purpose of this work will be analysed and executed using a case study method, were a set of user requirements are modelled in this research using algorithm1: 


\section{Algorithm 1: Proposed BPA Algorithm for Analysing User Tasks}

\section{Step 1. Get users story}

Step 2. Identify the tasks and activities

Step 3. Represent the tasks using a business process model (BPM)

Step 4. Repeat step 5 to 9

Step 5. Refine user tasks

Step 6 . Identify the roles for each tasks.

Step 7. If any complex processes, break into constituent tasks

Step 8. If decision points then analyse.

Step 9. Identify infrastructures required for implementation

Until refinement is no longer needed

\section{CASE STUDY: Hospital Information System}

To test the algorithm 1, a case study approach was used to obtain user requirements for an Information Systems Development Project using a Hospital as a Business Process. A Case study method enables a researcher to closely examine the data within a specific context. In most cases, a case study method selects a small geographical area or a very limited number of individuals as the subjects of study. Case studies, explore and investigate contemporary reallife phenomenon through detailed contextual analysis of a limited number of events or conditions, and their relationships (Yin, 1984). A formal interview protocol was used to study the business processes in Health Creed Hospital, a Private Clinic in Lagos State, Nigeria. The aim of the interview was to identify the business processes required in a hospital Information System. The Managing Director of the Hospital and heads of some selected departments were interviewed to determine the activities and task performed. The following tasks for a hospital information system were identified from the study:

$\begin{array}{ll}\text { 1. } & \text { Patient Registration } \\ \text { 2. } & \text { Doctor's Documentation } \\ \text { 3. } & \text { Billing } \\ \text { 4. } & \text { Laboratory Services } \\ \text { 5. } & \text { Pharmacy } \\ \text { 6. } & \text { Supply Chain Management } \\ \text { 7. } & \text { Consultant Details } \\ \text { 8. } & \text { Ward Details } \\ \text { 9. } & \text { Ambulance Services } \\ \text { 10. } & \text { Human Resource Management }\end{array}$

The next stage is to create a Business Process Model. This is modelled in Figure 2. 


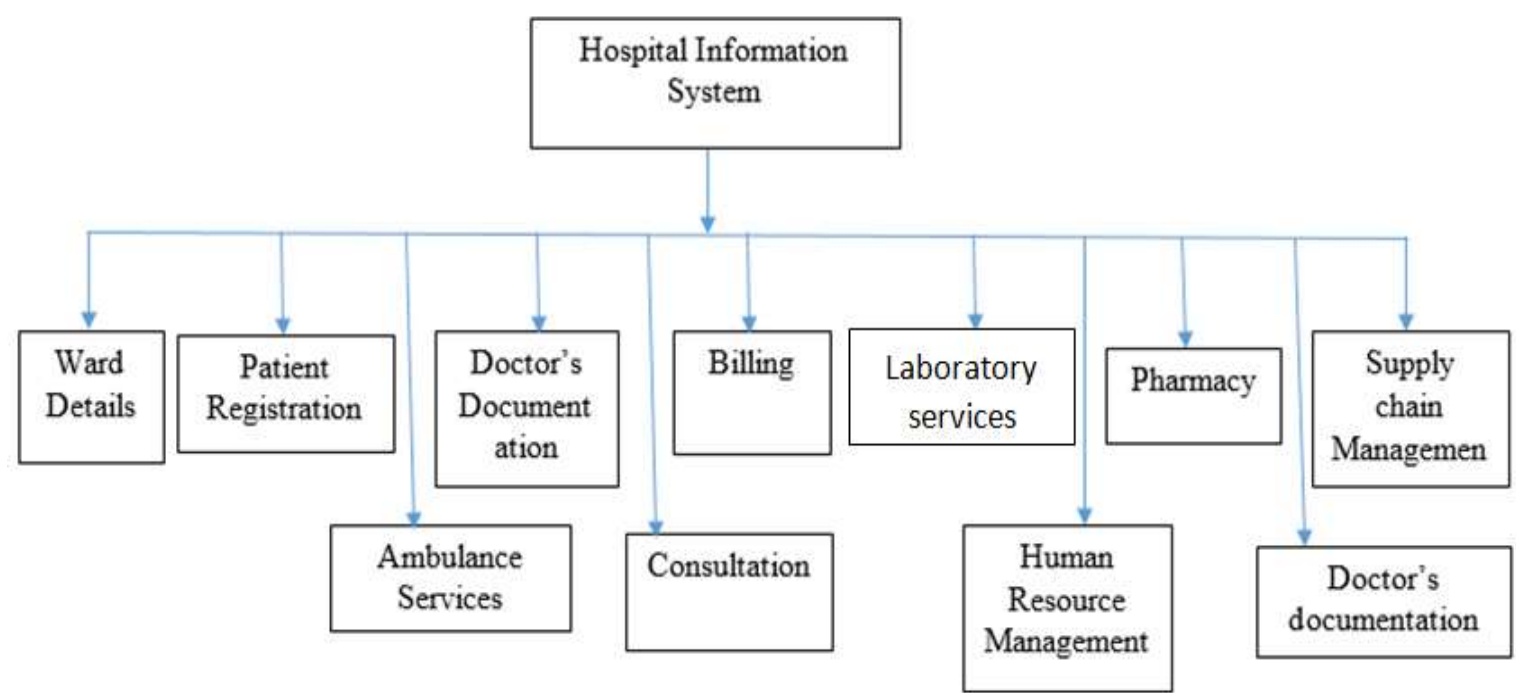

Figure 2: Tasks in a Hospital Information System

To identify appropriate parameters for cost estimation, each task is refined into component parts. At each stage of the refinement, the sub-processes required to accomplish the task, resources required, dependencies, decision points and the task complexity are identified. Figure 2 shows the activities and tasks for patient registration. Three sub-processes: old patient, new patient and emergency are identified. Each of these sub-processes are further decomposed into other sub-activities and tasks until each user task corresponds to an action or instruction.

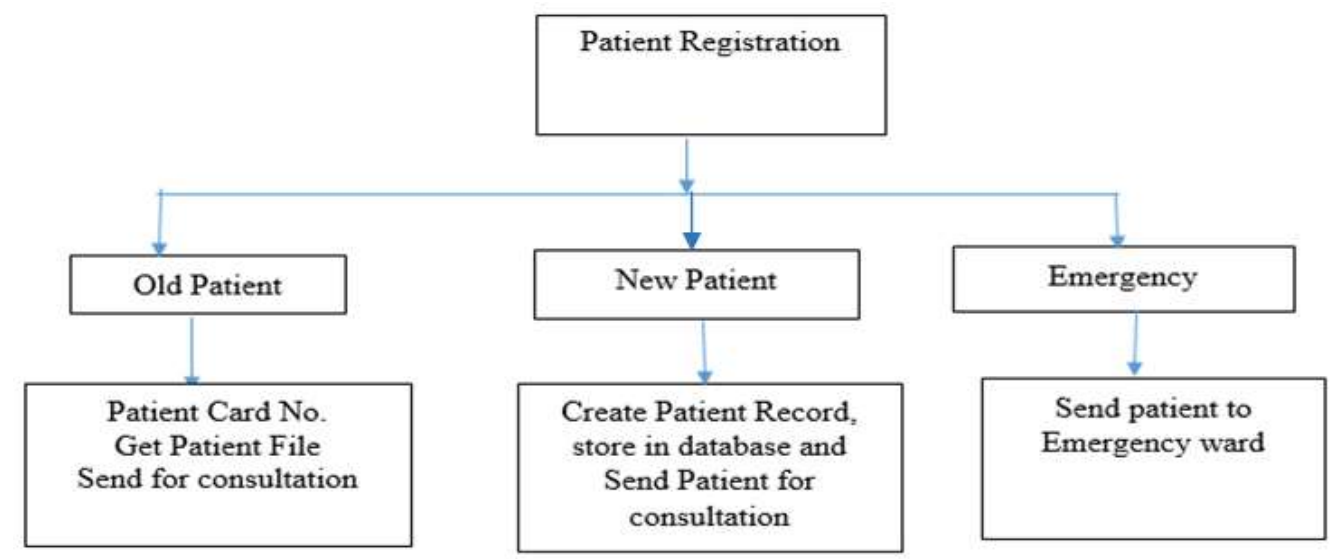

Figure 3: Patient Registration task Analysis

Figure 3: Patient Registration Task Analysis 
The activity Create Patient Record for new patients in Figure 3 includes the following action:



During the Analysis of the 'Patient Registration 'activity the following parameters that will guide a cost estimator were identified:

\section{A. Human Resource Needs \\ i. Software Developers \\ ii Database Administrator \\ iii Computer Operator \\ B. Computer Software \\ i. Database Management System \\ C. Decision Points}

A decision point is a stage in a process were judgement has to be made that affects the execution of the process. Decision points add complexity to a software system because each decision point requires further refinement that could create new processes (sub-processes) hence a cost estimator needs to identify decision points in the users requirements to guide the estimation process. The following decision points were identified for 'Patient Registration':

$\begin{array}{ll}\text { i } & \text { Patient Type () } \\ \text { ii } & \text { Patient Status () } \\ \text { iii } & \text { Referred () }\end{array}$




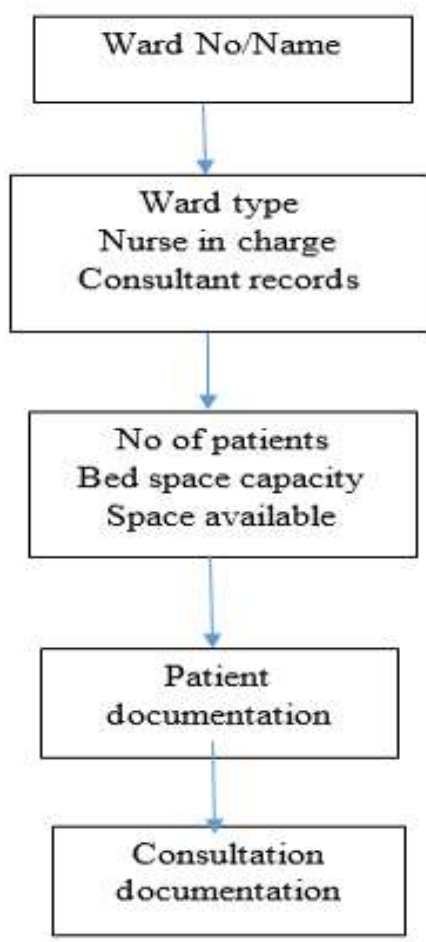

Figure 4: Ward

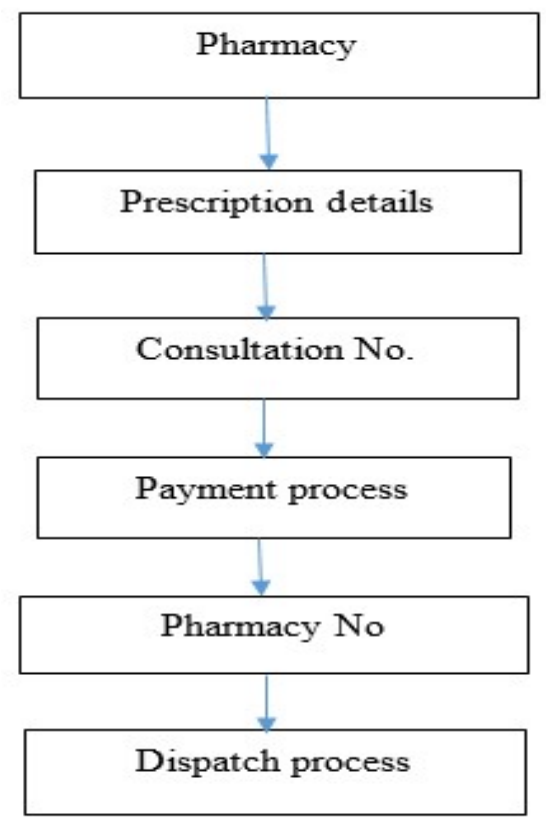

Figure 5: Pharmacy 


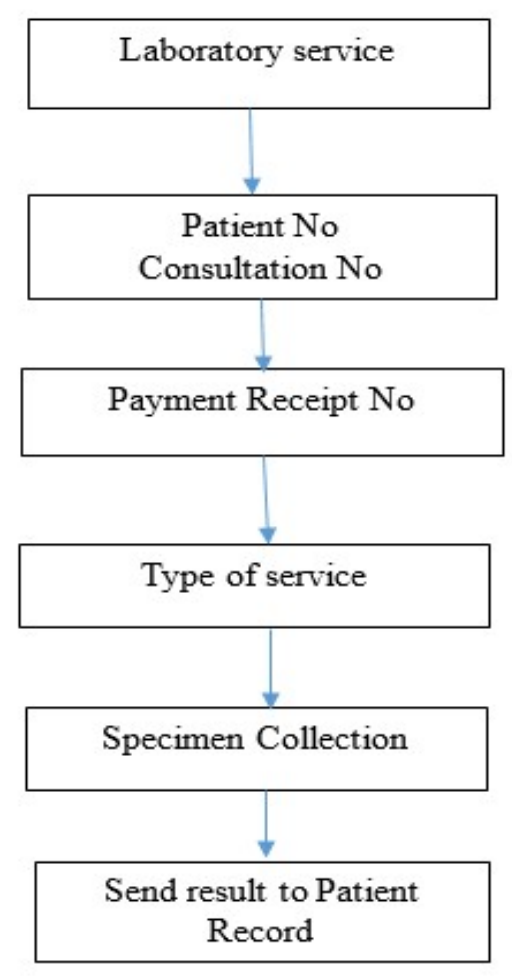

Figure 6: Laboratory Service

Each process $\mathrm{k}$ in the BPM is analysed and the parameters, $P_{i}^{k}(\mathrm{i}=1,2 \ldots \mathrm{n})$ are identified, were $\mathrm{n}$ is the total number of each parameter type.

To obtain the total parameters for cost estimation, we propose the following approach:

For each User Task $T_{\mathrm{k}}$ and Parameter type $P_{i}^{k}(\mathrm{i}=1 . . \mathrm{n})$, the parameter list, $\mathrm{PLT}_{\mathrm{k}}$ is given by:

$$
P L T_{k}=\sum_{i=1}^{n} P_{i}^{k}
$$

and the total parameter list TPL for the entire project is given by:

$$
T P L=\sum_{k=1}^{m} \sum_{i=1}^{n} P_{i}^{k}=\sum_{k=1}^{m} P L T_{k}
$$

where $\mathrm{m}$ is the total number of user tasks in the project 
The following were observed during the task analysis of the health creed Hospital tasks:

1. Human resource required:

- Developers

- Database administrators

- Network engineers

2. Decision points include patient category, test type, billing for pharmacy, laboratory, in-patient/out-patient etc.

3. Infrastructure

- Computers network

- Database system

- Other hardware/ software platforms required for implementation e.g programming languages, operating system, computers and accessories.

4. Users required for participating throughout the development process and the cost of engagement.

\section{CONCLUSION}

Software cost estimation is a major problem in software development, and it has been identified as one of the root causes of software project failures. A business process modelling approach was adopted as a precursor to cost estimation in a software development project in this paper. This approach was tested using a hospital information system as a single case study. Using the BPA algorithm, complex tasks and decision points that can create estimation bottlenecks are identified to enable a cost estimator make more informed decisions. In situations were expert opinion is the only available option, having a purview of the various tasks and organizations workflow will add more value to the estimators judgement. Because the user is actively involved and directs most of the business process activities, it is easy for the user to understand the approximate cost of each feature, which improves decision making and requests for new features will no longer sound out of context since the developers can predict users requests and create allowance to accommodate such requests into the current cost.

\section{REFERENCES}

1. Aldin, L and de Cesare, S. (2011). A literature review on business process modelling: new frontiers of reusability. Enterprise Information Systems. 1 - 25 iFirst Article

2. Abedallah Z., Mohd H. S., Abdual A. G., Rodziah Atan and Tieng W. K. (2008). Issues in Software Cost Estimation V8 p414 International Journal of Computer Science and Network Security

3. Dheeraj, R. and Gupta, K. (2016). Software Cost Estimation Techniques: A Review Of Literature. International Journal of Research and Development in Applied Science and Engineering (IJRDASE).

4. Lang, M.; Keaveney, S. and Conboy, K. (2011). Cost Estimation in Agile Software Development Projects. International Conference on Information Systems Development.

5. Marlon, D., Marcello, L., Jan M. and Hajo, A. R. (2013). Fundamentals of Business Process Mgmt p1-33.

6. Shekar, S. and Kumar, U. (2016). Review of Various Software Cost Estimation Techniques International Journal of Computer Applications (0975 - 8887 Volume 141 - No.11.

7. Yin, R.K., (1984). Case Study Research: Design and Methods. Beverly Hills, Calif: Sage Publications.

8. Yin, R., (1994). Case study research: Design and methods (2nd ed.). Beverly Hills, CA: Sage

9. Publishing.

10. Yan Z., Mazzara M., Cimpian E., Alexander U., (2007). Business Process Modelling: Classification and Perspective.

11. Aldin, Laden and de Cesare, Sergio(2011) 'A literature review on business process modelling: new frontiers of reusability', Enterprise Information Systems,, First published on: 07 April 2011 (iFirs 